\title{
Модифицированное нановолокно на основе полиакрилонитрила как сорбент для извлечения некоторых ионов тяжелых металлов
}

\author{
Данчук А.И. ${ }^{1}$, Грунова Ю.В. ${ }^{1}$, Доронин С.Ю. ${ }^{1}$, Лясникова А.В. ${ }^{2}$ \\ ${ }^{1}$ ФГБОУ ВО «Саратовский государственный университет имени Н.Г. Чернылевского», Саратов \\ ${ }^{2}$ ФГБОУ ВО «Саратовский государственный технический университет имени Ю.А. Гагарина», \\ Саратов
}

Поступила в редакцию 25.11.2017 г.

DOI: https://doi.org/10.17308/sorpchrom.2018.18/545

Предложены новые твердофазные сорбенты некоторых ионов тяжелых металлов $\left(\mathrm{Cu}^{2+}, \mathrm{Pb}^{2+}\right.$, $\left.\mathrm{Mn}^{2+}\right)$ на основе нановолокна, полученного методом бескапиллярного электроформования растворов полиакрилонитрила в диметилформамиде. Нановолокно модифицировали реакциями аминирования (ПАН-оксим) и щелочного гидролиза (ПАН-СООН). Проведена ИК-спектроскопическая идентификация синтезированных нетканых сорбентов и исследована их структура методом сканирующей электронной микроскопии. Удельные площади поверхности сорбентов ПАН-оксима и ПАН-СООН соответственно равны 19.9 и $6.20 \mathrm{~m}^{2} /$ г. Установлены оптимальные условия и основные сорбционные характеристики исследованных металлов в статических условиях. Величины сорбционных ёмкостей для $\mathrm{Cu}(\mathrm{II}), \mathrm{Pb}(\mathrm{II})$ и $\mathrm{Mn}(\mathrm{II})$ составили соответственно $(66 \pm 1),(72 \pm 2)$, и $(6 \pm 2)$ мг/Г для ПАН-СООН и (121 \pm 3$),(115 \pm 2)$ и $(14 \pm 3)$ мг/г для ПАН-оксима.

Ключевые слова: нановолокна, нетканые материалы, электроформование, полиакрилонитрил, сорбционное концентрирование, тяжёлые металлы.

\section{Modified polyacrylonitrile nanofiber material as a sorbent for some of heavy metal ions extraction}

\author{
Danchuk A.I. ${ }^{1}$, Grunova Yu.V. ${ }^{1}$, Doronin S.Yu. ${ }^{1}$, Lyasnikova A.V. ${ }^{2}$ \\ ${ }^{1}$ Saratov State University, Saratov \\ ${ }^{2}$ Saratov State Technical University, Saratov
}

\begin{abstract}
Heavy metal pollution is a serious problem, which can cause public health issues because heavy metals are not degradable and accumulate in organisms. Therefore, sensitive and simple determination of metal ions has proved to be extremely important. To increase the sensitivity of existing methods of heavy metal ions determination, solid phase extraction is used followed by spectrophotometric or AAS detection. In the last decade nonwoven materials (nanofibres) obtained from polymer solutions are used as an attractive alternative to traditional sorbents for heavy metals. The simplest and universal way to produce nonfibers is electrospinning. New solid-phase sorbents for some of heavy metal ions $\left(\mathrm{Cu}^{2+}, \mathrm{Pb}^{2+}, \mathrm{Mn}^{2+}\right)$ based on nanofiber materials obtained by non-capillary electrospinning technique from polyacrylonitrile (PAN) in dimethylformamide (DMF) solution were proposed.

To improve the sorption properties of the obtained nanofibers a directional chemical modification of initial PAN nanofiber nitrile groups is proposed by two reactions: alkaline hydrolysis with $\mathrm{NaOH}$ solution to form hydroxyl and carboxyl groups (PAN-COOH nanofiber); amination reaction with hydroxylamine in the presence of sodium carbonate to form amidoxime groups (PAN-oxime nanofiber). FT-IR spectroscopic identification of synthesized nonwoven sorbents was carried out and their structure was studied by scanning electron microscopy. The specific surface
\end{abstract}


areas of the PAN-oxime and PAN-COOH sorbents were 19.9 and $6.20 \mathrm{~m}^{2} / \mathrm{g}$ respectively. The optimal conditions and the main sorption characteristics for such metals as $\mathrm{Cu}$ (II), $\mathrm{Pb}$ (II) and $\mathrm{Mn}$ (II) under static sorption were established. The values of the sorption capacities for $\mathrm{Cu}$ (II), $\mathrm{Pb}$ (II) and $\mathrm{Mn}$ (II) were $66 \pm 1,72 \pm 2$, and $6 \pm 2 \mathrm{mg} / \mathrm{g}$ for PAN$\mathrm{COOH}$ and $121 \pm 3),(115 \pm 2)$ and $(14 \pm 3) \mathrm{mg} / \mathrm{g}$ for PAN-oxime.

Keywords: electrospun nanofibres, nonwoven materials, electrospinning, sorption, polyacrylonitrile, heavy metals.

\section{Введение}

Хорошо известно [1], что лимитируемые по ПДК тяжелые металлы, попадая в окружающую среду, способны накапливаться в организме человека. Чрезвычайно низкая их биодеградация приводит к обезвоживанию организма, разрушению нервной системы, раздражению слизистых оболочек, кожным высыпаниям, легочной недостаточности, повреждению печени и др. [2]. Контроль содержания тяжелых металлов, таких как свинец, хром, кобальт, никель, ртуть, кадмий, мышьяк и медь в объектах окружающей среды, пищевых продуктах является актуальной аналитической задачей и требует применения высокочувствительных методов определения. К таким методам относят атомно-абсорбционную спектрометрию, рентгено-флуоресцентрый анализ, спектрометрию с индуктивно-связанной плазмой и др. [3]. Однако, низкие значения ПДК на тяжелые металлы в ряде случаев требуют предварительного их сорбционного концентрирования, то есть применения сорбентов, обладающих высокой сорбционной активностью по отношению к ионам тяжелых металлов, оптимальной водопроницаемостью, возможностью регенерации и др.

В последнее десятилетие особое внимание уделяется нетканым материалам (нановолокнам), получаемым преимущественно из растворов полимеров или их композитов, которые обладают широким спектром областей применения, например, тканевая инженерия, системы доставки лекарств, в качестве нановолоконных мембран для тонкой фильтрации и защитной одежды [4]. Они являются привлекательной альтернативой традиционным сорбентам тяжелых металлов. Относительно высокая удельная поверхность, постоянная структура пор и возможность физической и химической модификации нановолокон приводит к улучшению ряда их сорбционных характеристик по сравнению с другими твердофазными сорбентами тяжелых металлов, такими как глины, смолы, пены и т.п.

Наиболее простым и универсальным способом получения нетканых материалов является электроформование [5]. Его применяют для получения нановолокон с заданными свойствами, при этом контролируют такие их характеристики, как плотность, толщину и пористость.

Целью настоящей работы явилось создание твердофазных нановолоконных сорбентов (нетканых материалов, $\mathrm{HM}$ ) тяжелых металлов (Pb, $\mathrm{Cu}, \mathrm{Mn})$ методом электроформования из растворов полиакрилонитрила (ПАН). Для улучшения сорбционных свойств полученных нановолокон предложен подход, состоящий в направленной химической модификации нитрильных групп исходного нетканого материала на основе ПАН двумя реакциями: щелочным гидролизом раствором $\mathrm{NaOH}$ с образованием гидроксильных и карбоксильных групп (нановолокно ПАН-СООН); реакцией аминирования с гидроксиламином в присутствии карбоната натрия с образованием амидоксимных групп (нановолокно ПАН-оксим).

\section{Эксперимент}

Для получения НМ на основе волокна «Нитрон», состоящего из полимера ПАН, применяли метод бескапиллярного электроформования на установке Elmarco 
«Nanospider NS Lab 200» (Чехия). Готовый формовочный 13\%-ный раствор полимера ПАН в диметилформамиде (ДМФА) объемом $100 \mathrm{~cm}^{3}$ помещали в гальваническую ванну для электроформования со струны в течение 1 часа в установленных оптимальных условиях: $U=70$ кB, $\mathrm{I}=0.02 \mathrm{~mA}$, расстояние между электродами (h)=180 мм. Давление пара ДМФА, выбранного в качестве растворителя ПАН, обеспечивало быстрое испарение и отверждение волокон при достижении коллектора. НМ формировался на подложке, в качестве которой служил «Спанбонд», который затем высушивали на воздухе в течение 24 ч при температуре $25^{\circ} \mathrm{C}$.

Методика модификации ПАН-нановолокна. Полученное ПАН-нановолокно модифицировали двумя способами. Первый способ аналогичен представленному в работе [6] и основан на обработке НМ при $70^{\circ} \mathrm{C}$ раствором солянокислого гидроксиламина в присутствии безводного карбоната натрия, взятых в соотношении 2:1 (0.3 М : $0.15 \mathrm{M})$ в течение 80 минут. Второй способ модификации НМ основан на реакции щелочного гидролиза нитрильных групп водным раствором щелочи $(\mathrm{NaOH}) 1,5$ и 10 масс. \% в течение 20, 40, 60 и 90 минут. Температура реакции фиксировали при $70^{\circ} \mathrm{C}$. Далее НМ промывали дистиллированной водой до нейтрального $\mathrm{pH}$ и сушили в течение 24 ч на воздухе при температуре $25^{\circ} \mathrm{C}$.

Изучение структуры полученного НМ. Для определения диаметра волокон исследуемых НМ получали микрофотографии поверхности образцов с помощью автоэмиссионного сканирующего электронного микроскопа MIRA 2 LMU, производства фирмы Tescan, оснащенного системой энергодисперсионного микроанализа INCA Energy 350 (Чехия). Контроль химической модификации ПАН нановолокон осуществляли ИК-Фурье спектроскопически с использованием спектрометра Nicolet 6700 THERMO SCIENTIFIC (CШA). Определение удельной поверхности $\left(\mathrm{S}_{\text {уд }}\right)$ нановолокон ПАН, ПАН-СООН и ПАН-оксим проводили методом низкотемпературной адсорбции азота по Брунауэру-Эммету-Теллеру (БЭТ), а также определение объема микропор проводили методом Дубинина-Радушкевича на быстродействующем анализаторе удельной площади поверхности Quantachrome NOVA 2000e (США). Время вакуумирования - 4 ч.

Методика проведения сорбции ионов металлов (свинца, меди, марганца). Для изучения сорбции ионов металлов в статическом режиме исследуемые образцы НМ помещали соответственно в раствор нитрата свинца (II), хлорида меди (II) или сульфата марганца (II) с различными концентрациями и выдерживали при комнатной температуре в течение $0.5 ; 1 ; 2 ; 4 ; 6 ; 10$ и 24 ч при непрерывном перемешивании на горизонтальном шейкере. Остаточную концентрацию ионов металлов в растворе определяли на спектрофотометре Shimadzu UV-1800 (Япония). Концентрацию ионов свинца (II) и марганца (II) определяли спектрофотометрически с пиридилазорезорцином (ПАР). Для построения градуировочных зависимостей готовили растворы с молярными концентрациями свинца (II) и марганца (II) в интервале от 0.4 до 8 мг/дм ${ }^{3}$ и от 0.1 до 0.8 мг/дм ${ }^{3}$ соответственно. Градуировочные графики описываются уравнениями $y=f(c): y=0.190 c$ $\left(\mathrm{R}^{2}=0.999\right)$ для ионов свинца; $y=1.34 c\left(\mathrm{R}^{2}=0.997\right)$ для ионов марганца. Для оценки остаточной концентрации этих металлов после сорбции отбирали 500 мкл соответствующего раствора, переносили в пробирки Эппендорфа, добавляли 150 мкл $1 \cdot 10^{-3} \mathrm{M}$ водного раствора ПАР, 350 мкл ацетатно-аммиачного буферного раствора $(\mathrm{pH}=10)$ и доводили до $1.5 \mathrm{~cm}^{3}$ бидистиллированной водой. Полученные растворы фотометрировали при $\lambda_{\max }=520$ нм (свинец), при $\lambda_{\max }=500$ нм (марганец) относительно $5 \cdot 10^{-8} \mathrm{M}$ водного раствора ПАР.

Концентрацию ионов меди (II) определяли дифференциальнофотометрически с реактивом «Тетра», согласно [8]. По полученным экспериментальным данным рассчитывали количественные характеристики сорбции металлов: 
степень извлечения $(R, \%)$ и сорбционную ёмкость $(Q$, мг/г) согласно уравнениям $(1,2)$ :

$$
\begin{gathered}
R, \%=\frac{c_{o}-c}{c_{o}} \cdot 100 \\
Q, \mu ح / 2=\frac{\left(c_{o}-c\right) \cdot V}{m}
\end{gathered}
$$

где $c_{0}$ и $c$ - концентрации определяемого катиона металла до и после сорбции соответственно, мг/дм ${ }^{3}, \mathrm{~V}$ - объем водного раствора, дм ${ }^{3} ; \mathrm{m}$ - масса сорбента, г.

Для изучения кинетики сорбции ионов металлов модифицированное нановолокно (по 0.020 г) помещали в конические колбы вместимостью $100 \mathrm{~cm}^{3}$, добавляли $25 \mathrm{~cm}^{3}$ анализируемых растворов ионов металлов с концентрацией 20 мг/дм ${ }^{3}$ и перемешивали на горизонтальном шейкере. Через равные промежутки времени отбирали аликвотную часть $\left(0.5 \mathrm{~cm}^{3}\right)$ раствора соответствующего металла, переносили в пробирки Эппендорфа и фотометрически определяли их остаточную концентрацию с реагентом ПАР как описано выше.

Изучение влияния рН растворов на сорбцию ионов металлов проводили в статических условиях с учетом кинетики сорбции с использованием ацетатноаммиачных буферных растворов в интервале $\mathrm{pH}$ 4.0-7.0. Концентрация металлов со-

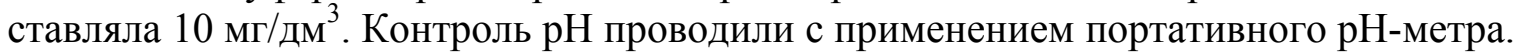

Методика атомно-абсорбционного определения $\mathrm{Pb}$ (II) и $\mathrm{Cu}$ (II). Для определения остаточных концентраций ионов $\mathrm{Pb}^{2+}$ и $\mathrm{Cu}^{2+}$ на уровне ПДК и ниже после их сорбции на ПАН-СООН и ПАН-оксиме применяли метод атомно-абсорбционной спектрометрии (AAC) с применением спектрометра Shimadzu AA-7000 с электротермической атомизацией (ЭТА). Для построения градуировочных зависимостей оптическая плотность $(A)$ - концентрация $\left(c\right.$, мкг/дм $\left.{ }^{3}\right)$ металлов готовили их стандартные растворы из ГСО для ионов $\mathrm{Pb}^{2+}$ и $\mathrm{Cu}^{2+}$ в диапазонах от 4 до $20 \mathrm{мкг/дм}{ }^{3}$ и от 2 до 8 мкг/дм ${ }^{3}$ соответственно. Аликвоты приготовленных растворов объёмом 20 мкл вносили в графитовую печь с пиропокрытием и фиксировали поглощение резонансного излучения при 283.3 нм для свинца и 324.8 нм для меди $(n=3, P=0.95)$.

\section{Обсуждение результатов}

Характеристика полученных нановолокон. Предварительно полученные методом электроформования нетканые материалы на основе ПАН модифицировали реакциями аминирования (первый способ) и щелочного гидролиза (второй способ). Контроль превращения нитрильных групп в амидоксимные осуществляли ИКспектроскопически и расчетом степеней конверсии. Полученные результаты подробно описаны нами в [6].

Второй способ модификации ПАН-нановолокна основан на нижеприведённой схеме [7].<smiles>CCC(CC(C)CC(C)CC(C)C)C(C)C</smiles>

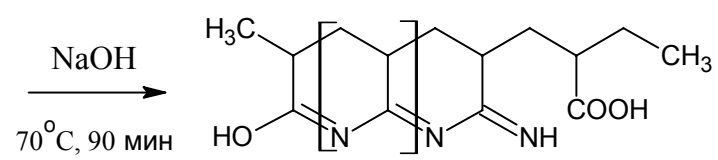

Щелочной гидролиз ПАН сопровождался изменением цвета нановолокна от белого до желтовато-коричневого при увеличении массовой доли модифицирующего агента $(\mathrm{NaOH})$ от 1 до 10\% и времени модификации от 20 до 90 минут. На рис. 1 представлены ИК-спектры модифицированных волокон ПАН-СООН.

Увеличение концентрации $\mathrm{NaOH}$ приводило к уменьшению интенсивностей пиков при $2242 \mathrm{~cm}^{-1}, 1452 \mathrm{~cm}^{-1}$, характерных для групп -C $\equiv \mathrm{N}$ и $-\mathrm{O}-\mathrm{CH}_{3}$ соответственно. Превращение эфирной группы в карбоксильную сопровождалось появлением 
широкой полосы при $3357 \mathrm{~cm}^{-1}$, соответствующей колебанию -ОН группы. Кроме того, в ИК-спектре появляется новый пик при $1578 \mathrm{~cm}^{-1}$, который соответствует иминным конъюгированным (пиридиновым) фрагментам в модифицированном волоконе ПАН-СООН.

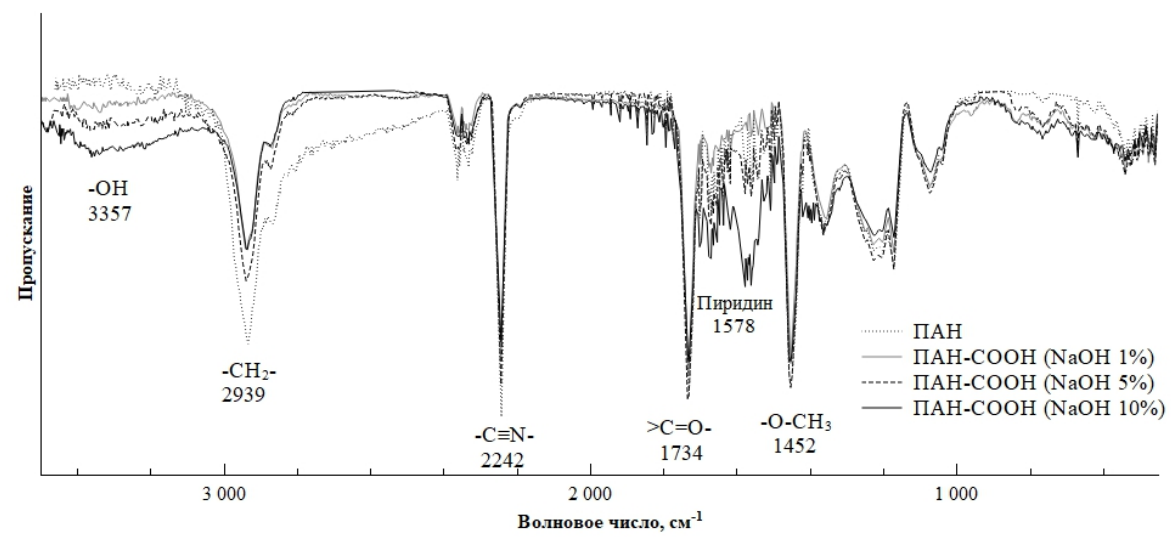

Рис. 1. ИК-Фурье спектры исходного нановолокна (ПАН) и после его модификации 1, 5 и 10\%-ным водным раствором $\mathrm{NaOH}$ (нановолокно ПАН-СООН).

При выборе оптимальной концентрации модифицирующего агента $(\mathrm{NaOH})$ учитывали два фактора: морфологию нановолокна и его сорбционные свойства. Так, на рис. 2 представлены электронные микрофотографии исходного нановолокна ПАН (рис. $2 a$ ) и модифицированного материала ПАН-СООН (рис. 2 б, в).

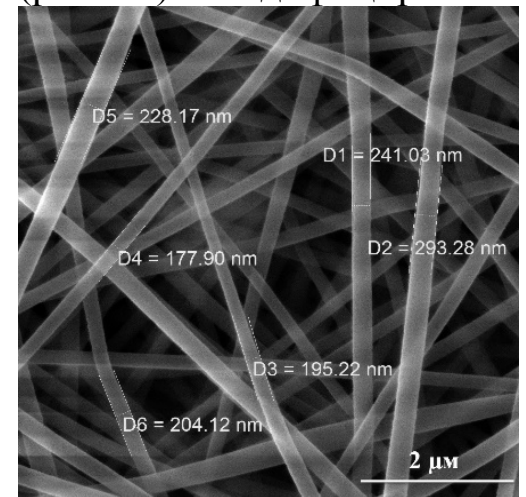

a

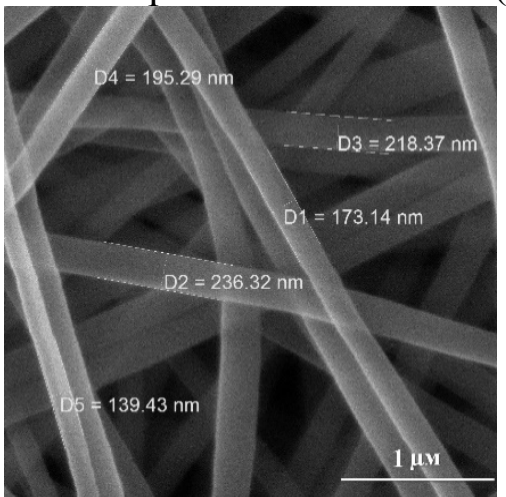

6

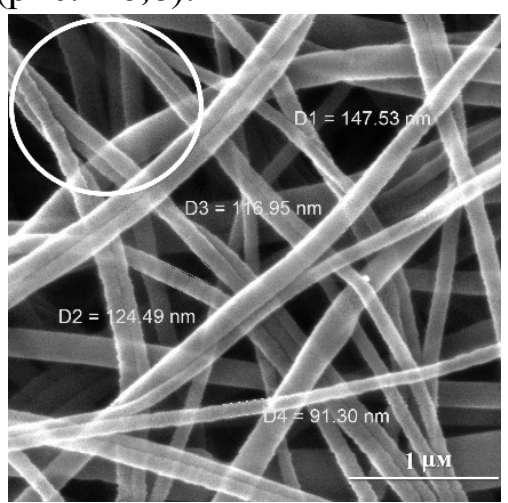

B

Рис. 2. Микрофотографии нановолокон ПАН, полученные с помощью сканирующей электронной микроскопии: исходного $(a)$; модифицированного $1 \%$-ным (б) и 5\%-ным (в) раствором $\mathrm{NaOH}$.

Нановолокна ПАН и ПАН-СООН имеют схожую структуру, в поперечном сечении - округлую форму. Поверхности нановолокон однородны и не имели видимых дефектов при модификации материала раствором $\mathrm{NaOH}$ до 5\% (рис. 2б). Увеличение концентрации $\mathrm{NaOH}$ от $5 \%$ и более приводило к изменению структуры нановолокон. Так, например, на рис. 26 показан отдельный участок с дефектом нановолокна, при этом поверхность становилась шероховатой, а при концентрации $\mathrm{NaOH} 10 \%$ и выше отмечалась его сильная усадка. Средние диаметры отдельных волокон исходного материала ПАН находились в пределах от 170 до 300 нм, однако после гидролиза раствором $\mathrm{NaOH}$ размеры волокон ПАН уменьшались. Так, например, при обработке 1\%-ным раствором щелочи средний диаметр волокон составил (130-240) нм, а при концентрации $\mathrm{NaOH} 5 \%-(90-150)$ нм.

Оптимальную концентрацию модифицирующего агента также устанавливали на примере сорбции свинца нановолокном ПАН-СООН (рис. 3). 


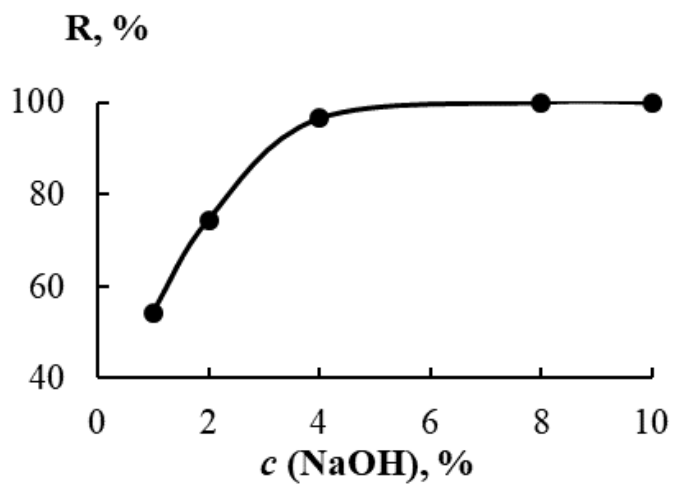

Рис. 3. Зависимость степени извлечения $(R)$ ионов $\mathrm{Pb}^{2+}$ от концентрации $\mathrm{NaOH} ; c\left(\mathrm{~Pb}^{2+}\right)=20$ мг/дм ${ }^{3}$.

Как видно из рис. 3 , степень извлечения ионов свинца достигалась 100\%, начиная с концентрации $\mathrm{NaOH}-5 \%$, при этом, дальнейший рост концентрации щёлочи, независимо от морфологии нановолокна (наличие вышеуказанных дефектов), позволял достигать $100 \%$ степени извлечения ионов $\mathrm{Pb}^{2+}$.

Для нановолокон ПАН, ПАН-СООН и ПАН-оксим методами БЭТ и Дубинина-Радушкевича определены удельные площадь поверхности и объём, средний радиус пор (табл. 1). Из табл. 1 видно, что удельная площадь поверхности исходного материала ПАН $\left(33.1 \mathrm{~m}^{2} / \Gamma\right)$, с одной стороны, уступает существующим твердофазным сорбентам тяжелых металлов, например, наночастицы (НЧ) $\mathrm{TiO}_{2}\left(\mathrm{~S}_{\text {уд }}-186 \mathrm{~m}^{2} / \Gamma\right)$, аморфный оксид $\gamma-\mathrm{Fe}_{2} \mathrm{O}_{3}\left(\mathrm{~S}_{\text {уд }}-178-198 \mathrm{~m}^{2} / \Gamma\right)$ [9], кремнезем Силохром C-80, модифицированный полигексаметиленгуанидином и 8 -оксихинолин-5-сульфокислотой $\left(\mathrm{S}_{\text {уд }}\right.$ исходного сорбента - $80 \mathrm{~m}^{2} /$ ) [10], глауконит, модифицированный нановолокнами $\mathrm{AlOOH}\left(\mathrm{S}_{\text {уд }}-61 \mathrm{~m}^{2} / \Gamma\right)$ [11] и др. С другой стороны, сорбционные ёмкости некоторых из указанных сорбентов имеют более низкие значения $\left(\mathrm{Q}_{\mathrm{TiO} 2}\left(\mathrm{~Pb}^{2+}\right)=82 \mathrm{Mг} / \Gamma, \mathrm{Q}_{\gamma \text {-Fe2O3 }}\right.$ $\left.\left(\mathrm{Cu}^{2+}\right)=6.5 \mathrm{M \Gamma} / \Gamma\right)$.

Таблица 1. Результаты обработки экспериментальных данных методами БЭТ и Дубинина-Радушкевича

\begin{tabular}{|c|c|c|c|}
\hline Материал & $\begin{array}{c}\text { П порамерхености } \\
\text { (удельная), } \mathrm{m}^{2} / \Gamma\end{array}$ & $\begin{array}{c}\text { V пор (удельный), } \\
\text { см }^{3} / \Gamma\end{array}$ & $\begin{array}{c}\text { Средний радиус пор, } \\
\text { нм }\end{array}$ \\
\hline ПАН & 33.1 & 0.018 & 2.04 \\
\hline ПАН-СООН* & 19.9 & 0.011 & 2.14 \\
\hline ПАН-оксим & 6.20 & 0.003 & 2.38 \\
\hline
\end{tabular}

* Обработка волокна ПАН 1\%-ным раствором $\mathrm{NaOH}$

Основной вклад в сорбцию ионов металлов для большинства из вышеуказанных сорбентов вносит электростатическое взаимодействие и хемосорбция. В этом случае величина сорбционной ёмкости преимущественно зависит от количества хелатных центров сорбента и в меньшей степени от удельной площади поверхности. Так, направленная модификация исходного нановолокна ПАН как $\mathrm{NaOH}$, так и гидроксиламином, приводила к снижению значений удельной поверхности нановолокон и удельного объема в 2-5 раз. Однако предварительные исследования показали, что по мере уменьшения удельной площади поверхности нановолокон их сорбционная ёмкость возрастала, что и связано с увеличением количества лигандных групп в ПАН-СООН и ПАН-оксиме. При этом средний радиус пор незначительно увеличивался от 2.04 до 2.38 нм. 


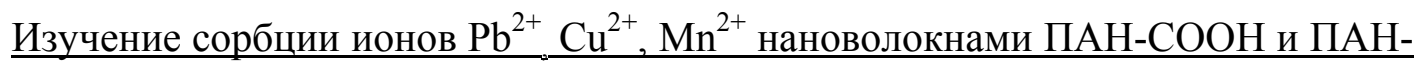
оксимом. Изотермы сорбции исследуемых ионов металлов на модифицированных нановолокнах ПАН-СООН и ПАН-оксим в оптимальных условиях приведены на рис. $4 a$ с учетом кинетики их сорбции в статических условиях (рис. 4б) и $\mathrm{pH}$ (рис. $5 a$ ), которые имеют классический Ленгмюровский вид, что указывает на мономолекулярный характер их сорбции.

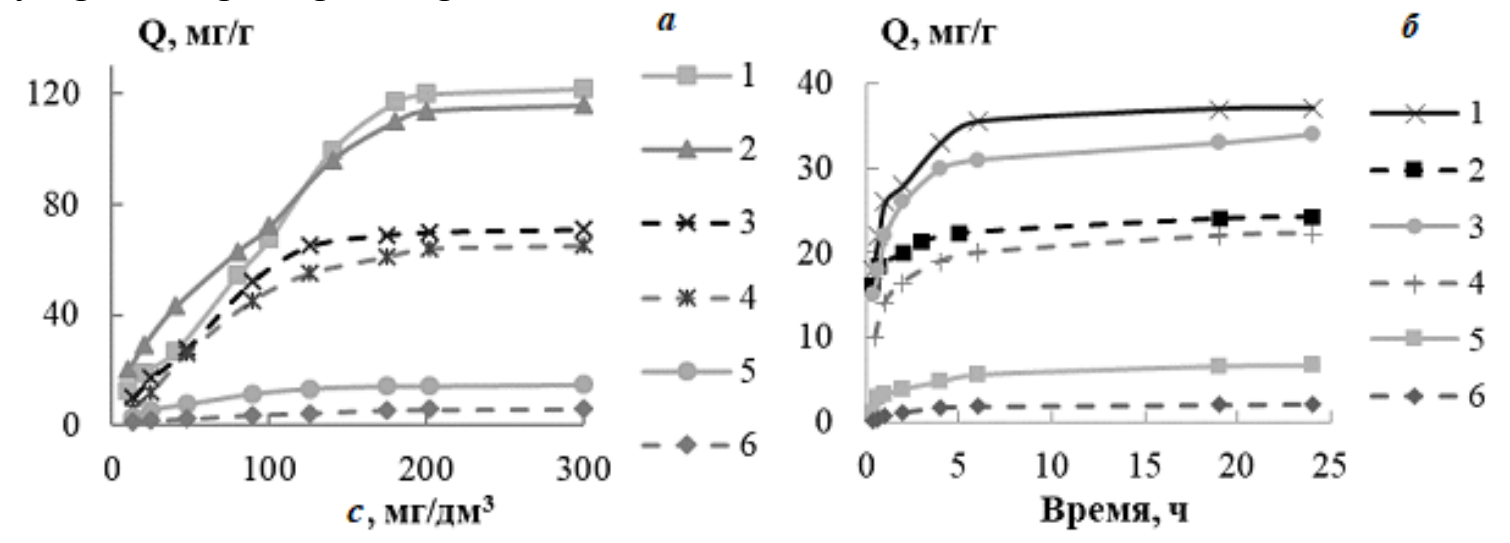

Рис. 4. Сорбционные характеристики материалов ПАН-СООН (пунктирная линия) и ПАН-оксим (сплошная линия), $\mathrm{Cu}^{2+}(1,4), \mathrm{Pb}^{2+}(2,3), \mathrm{Mn}^{2+}(5,6)$. ) Изотермы сорбции. б) Кинетика сорбции, $c=20 \mathrm{мг} /$ дм$^{3}$ (для всех ионов металлов), $\mathrm{V}=25 \mathrm{~cm}^{3}$.

Установлено, что для ионов $\mathrm{Cu}^{2+}, \mathrm{Pb}^{2+}$ и $\mathrm{Mn}^{2+}$ величины сорбционных ёмкостей нановолокон ПАН-СООН, согласно данным табл. 2, составили соответственно $(66 \pm 1),(72 \pm 2)$, и $(6 \pm 2)$ мг/г. Величины сорбционных ёмкостей для ПАН-оксима превысили аналогичные значения для ПАН-СООН соответственно в 1,8, 1,6 и 2,3 раза.

Таблица 2. Средние значения $(n=3, P=0.95)$ сорбционных ёмкостей $(Q)$ и степеней извлечения $(R)$ для нановолокон ПАН-СООН (1) и ПАН-оксим (2) по отношению к ионам меди, свинца и марганца

\begin{tabular}{|c|c|c|c|c|c|c|c|c|c|c|c|c|}
\hline \multirow{2}{*}{$\begin{array}{c}\mathcal{c}_{\text {исх }} \\
\text { мг/дм }\end{array}$} & \multicolumn{9}{|c|}{$\mathrm{Q}, \mathrm{мг} / \Gamma$} & \multicolumn{6}{c|}{$\mathrm{R}, \%$} \\
\hline & \multicolumn{1}{|c|}{$\mathrm{Cu}(\mathrm{II})$} & \multicolumn{2}{c|}{$\mathrm{Pb}(\mathrm{II})$} & \multicolumn{2}{c|}{$\mathrm{Mn}(\mathrm{II})$} & \multicolumn{2}{c|}{$\mathrm{Cu}(\mathrm{II})$} & \multicolumn{2}{c|}{$\mathrm{Pb}(\mathrm{II})$} & \multicolumn{2}{c|}{$\mathrm{Mn}(\mathrm{II})$} \\
\hline & 1 & 2 & 1 & 2 & 1 & 2 & 1 & 2 & 1 & 2 & 1 & 2 \\
\hline 10 & 6.1 & 12.2 & 10.0 & 18.9 & 1.2 & 3.2 & 85.2 & 92.7 & 77.2 & 93.8 & 9.7 & 16.7 \\
\hline 20 & 12.1 & 19.1 & 17.0 & 32.3 & 1.8 & 5.5 & 66.1 & 73.4 & 55.3 & 89.9 & 5.5 & 16.4 \\
\hline 40 & 26.2 & 26.7 & 28.0 & 47.8 & 2.4 & 7.6 & 54.1 & 63.9 & 37.8 & 69.8 & 4.5 & 8.4 \\
\hline 80 & 45.5 & 54.6 & 52.0 & 63.1 & 3.8 & 11.2 & 36.1 & 56.2 & 35.0 & 49.5 & 3.2 & 7.9 \\
\hline 100 & 55.2 & 67.4 & 65.0 & 71.0 & 4.5 & 13.2 & 30.5 & 54.1 & 27.0 & 41.5 & 2.8 & 8.3 \\
\hline 140 & 61.0 & 99.7 & 69.0 & 96.2 & 5.6 & 14.1 & 28.3 & 49.5 & 23.0 & 39.2 & 2.5 & 6.3 \\
\hline 180 & 64.0 & 117 & 70.0 & 109 & 5.7 & 14.1 & 23.2 & 45.3 & 20.0 & 37.1 & 1.6 & 5.9 \\
\hline 200 & 65.7 & 120 & 71.0 & 114 & 5.8 & 14.2 & 22.1 & 39.2 & 18.0 & 31.0 & 1.5 & 5.2 \\
\hline 300 & 66.0 & 121 & 72.0 & 115 & 6.0 & 14.3 & 14.4 & 25.3 & 12.0 & 22.8 & 1.2 & 4.1 \\
\hline
\end{tabular}

Влияние $\mathrm{pH}$ изучено в интервале 4.0-7.0 на примере сорбции ионов $\mathrm{Cu}^{2+}, \mathrm{Pb}^{2+}$ и $\mathrm{Mn}^{2+}$ нановолокном ПАН-оксим. Данный интервал $\mathrm{pH}$ обусловлен состоянием и формами металлов (ионы и гидроксокомплексы), рекомендуемыми в [12]. Как видно из рис. $5 a$, для всех ионов металлов наблюдались незначительные изменения степеней извлечения в диапазоне $\mathrm{pH}$ растворов от 4.0 до 7.0, что позволяет в дальнейшем работать без добавления буферных растворов в системы и не контролировать $\mathrm{pH}$ при изучении сорбции. 

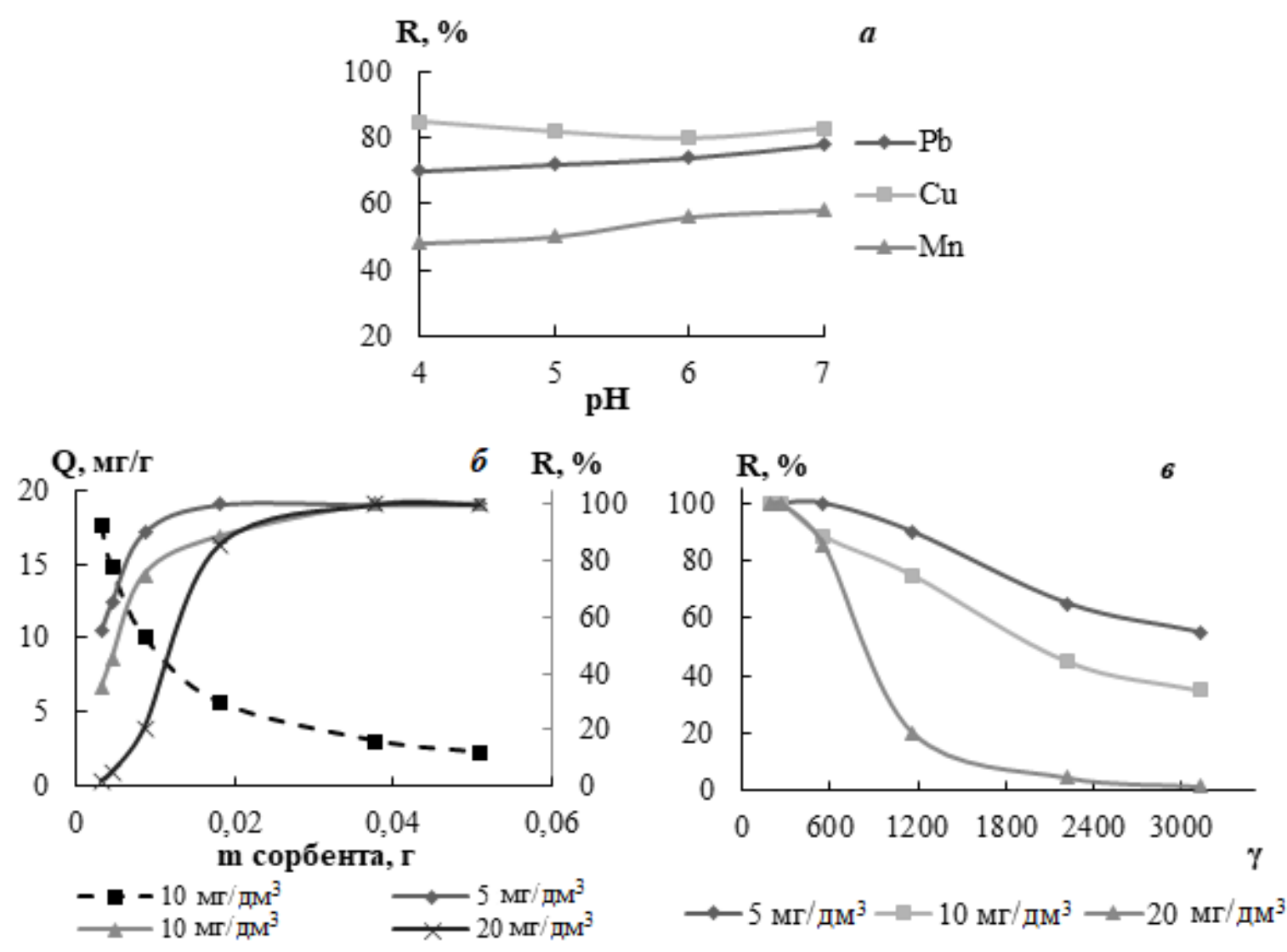

Рис. 5. Зависимость степени извлечения $(R)$ (сплошная линия) ионов металлов и сорбционной ёмкости $(Q)$ (пунктирная линия) на ПАН-оксиме от: $a) \mathrm{pH}$ растворов,

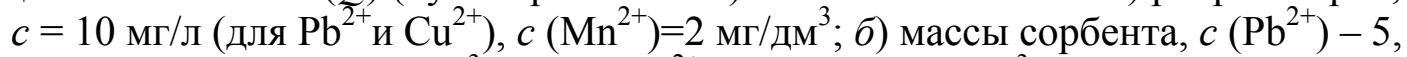
$10,20 \mathrm{мг} /$ дм$^{3} ;$ в) $\gamma, c\left(\mathrm{~Pb}^{2+}\right)-5,10,20 \mathrm{мг} /$ дм$^{3}$.

Полученные экспериментальные данные (табл. 2) свидетельствуют о том, что ионы свинца и меди сорбируются лучше, чем ионы марганца на обоих типах сорбентов, что может быть связано с различной способностью металлов вступать в реакции комплексообразования с группами волокон ПАН-СООН и ПАН-оксим. Так, согласно справочным данным [13-14], показатели констант нестойкости ( $\left.\mathrm{pK}_{1}\right)$ ацетатных комплексов для ионов свинца, меди и марганца составляют соответственно $2.5,2.2,1.2$; с ЭДТА - $10.6,11.5,6.9$; с 8-оксихинолином - 9.02, $12.2,6.8$; с $\alpha$-нитрозо- $\beta$-нафтолом значения $\mathrm{pK}_{1}$ для $\mathrm{Cu}^{2+}$ составил 12.5 , а для $\mathrm{Pb}^{2+}-9.7 ;$ с салицилальдоксимом для $\mathrm{Cu}^{2+}$ - 11.0, для $\mathrm{Mn}^{2+}-5.8$. Комплексообразующие группы указанных веществ схожи с группами модифицированных нановолокон ПАН-СООН и ПАН-оксима в настоящем исследовании, в связи с чем константы нестойкости можно аппроксимировать на нашу систему и, тем самым, объяснить механизм сорбции ионов. Кроме того, известно, что с увеличением ионного радиуса одинаково заряженных ионов металлов по отношению к ним увеличивается поглощающая способность полярных сорбентов [15]. Данная закономерность связана с меньшей склонностью ионов металлов с большим радиусом образовывать гидратные оболочки, которые снижают силы электростатического притяжения, что также доказывает лучшую сорбционную способность материалов по отношению к ионам свинца и меди (меньшие гидратные оболочки) в сравнении с ионами марганца.

Сорбционное концентрирование тяжёлых металлов на уровне долей ПДК одна из важнейших задач аналитической химии. Важным фактором для решения этой задачи является расчет наименьшей массы сорбента, достаточной для $\sim 100 \%$ 
степени извлечения ионов металлов из заданного объёма (массы) анализируемого водного объекта. Для этого, на примере нановолокна ПАН-оксим (рис. 5 б,в), изучено влияние соотношения массы исходного раствора к массе сорбента $(\gamma=\mathrm{m}$ раствора $/$ $\mathrm{m}$ сорбента ) на степень извлечения и сорбционную ёмкость ионов $\mathrm{Pb}^{2+}$. Так, с увеличением массы сорбента и уменьшением $\gamma$, степень извлечения ионов свинца возрастала до 100\%. При этом, сорбционная ёмкость не достигала своего предельного значения (рис. 5б). Таким образом, параметр $\gamma$ позволяет рассчитать минимальную массу сорбента для количественного извлечения тяжёлых металлов в интервале концентраций линейного участка соответствующих изотерм сорбции.

Для выбора оптимального значения $\gamma$ также исследована сорбция ионов меди и свинца в диапазоне их концентраций от 20 до 200 мкг/дм ${ }^{3}$ на примере сорбента ПАНоксим. Остаточные концентрации металлов определяли методом ААС (табл. 3).

Таблица 3. Степени извлечения и результаты ААС-определения ионов $\mathrm{Cu}^{2+}$ и $\mathrm{Pb}^{2+}$ в модельных растворах

\begin{tabular}{|c|c|c|c|c|}
\hline $\begin{array}{c}\text { Сорбируемый ПАН- } \\
\text { оксимом металл }\end{array}$ & $\begin{array}{c}\text { ПдК, } \\
\text { мкг/дм }\end{array}$ & $\begin{array}{c}\text { Исходная } \\
\text { концентрация } \\
\text { металла, мкг/дм }\end{array}$ & $\begin{array}{c}\text { Остаточная } \\
\text { концентрация } \\
\text { металла, мкг/дм }\end{array}$ & $\mathrm{R}, \%$ \\
\hline \multirow{2}{*}{$\mathrm{Cu}^{2+}$} & 1 & 20 & 0.1 & 99.5 \\
\hline $\mathrm{Pb}^{2+}$ & 6 & 200 & 1.9 & 98.2 \\
& \multirow{2}{*}{6} & 20 & 4.1 & 98.0 \\
\hline
\end{tabular}

Как видно из табл. 3, для достижения $~ 100 \%$-ной степени извлечения ионов металлов с концентрацией не более 200 мг/дм³ оптимальная величина $\gamma$ составила $270 \pm 30$.

\section{Заключение}

Исследованы сорбционные свойства полученных методом электроформования нетканых материалов на основе ПАН. Направленная модификация ПАН-нановолокна реакциями аминирования и щелочного гидролиза позволила придать нановолокну хемосорбционные свойства, что дает возможность использовать ПАН-оксим и ПАН$\mathrm{COOH} \mathrm{в} \mathrm{качестве} \mathrm{новых} \mathrm{эффективных} \mathrm{твердофазных} \mathrm{сорбентов} \mathrm{для} \mathrm{концентрирования}$ ионов металлов в водных средах в диапазоне $\mathrm{pH}$ 4.0-7.0. Методами ИКспектроскопии, сканирующей электронной микроскопии, БЭТ исследована структура полученных нановолокон ПАН-СООН и ПАН-оксим.

Определено оптимальное соотношение массы раствора к массе сорбента $(265 \pm 30)$, позволяющее сорбировать ионы металлов из водных сред со степенью извлечения, близкой к 100\%. Построены изотермы сорбции в оптимальных условиях с учетом кинетики сорбции и рН. Так, максимальное количество адсорбированных ионов $\mathrm{Cu}^{2+}, \mathrm{Pb}^{2+}$ и $\mathrm{Mn}^{2+}$ на материале ПАН-СООН составляло $(66 \pm 1)$, $(72 \pm 2)$, и $(6 \pm 2)$ мг/г соответственно. Значения максимальных сорбционных ёмкостей для ПАН-оксим превышают данные значения для ПАН-СООН соответственно в 1.8 , 1.6 и 2.3 раза $(121 \pm 3),(115 \pm 2)$ и $(14 \pm 3)$ мг/г.

\section{Список литературы}

1. Будников Г.К. // Соросовский образовательный журнал. 1998. № 5. С. 23-29. 
2. Теплая Г.А. // Астраханский вестник экологического образования. 2013. Т. 1. № 23. C. 182-192.

3. Линник Р.П., Линник П.Н., Запорожец О.А. // Mетоды и объекты химического анализа. 2006. Т.1. № 1. С. 4-26.

4. Махова Т.М., Доронин С.Ю. // Бутлеровские сообщения. 2018. Т. 3. № 53. C.55-66.

5. Матвеев А.Т., Афанасов И.М. Получение нановолокон методом электроформования. Учебное пособие. М. Московский государственный университет. 2010. 83 с.

6. Данчук А.И., Махова Т.М., Доронин С.Ю., Махов С.В. и др. // Бутлеровские сообщения. 2016. Т.48. №11. С. 123-131.

7. Kampalanonwat P., Supaphol P. // Ind. Eng. Chem. Res. 2011. Vol. 50. pp. 11912-11921.

8. Чернова Р.К., Кулапина Е.Г., Русанова Т.Ю., Доронин С.Ю. Практикум по аналитической химии. Ч.1. Учебное пособие. Саратов. Саратовский государственны университет. $2015.120 \mathrm{c}$.

9. Hua M., Zhang S., Pan B., Zhang W. et al. // Journal of Hazardous Materials. 2012. Vol. 211-

\section{References}

1. Budnikov H.C., Soros educational journal, 1998, Vol. 5, pp. 23-29.

2. Teplaja G.A., Astrakhan Bulletin for Environmental Education, 2013, Vol. 1, No.23, pp. 182-192.

3. Linnik R.P., Linnik P.N., Zaporozhec O.A., Methods and objects of chemical analysis, 2006, Vol. 1, No 1, pp. 4-26.

4. Makhova T.M., Doronin S.Yu., Butlerov Communications, 2018, Vol. 53, No 3, pp. 55-66.

5. Matveev A.T., Afanasov I.M., Poluchenie nanovolokon metodom elektroformovanija. Uchebnoe posobie. Moskow, Moskow state university Publ., 2010, 83 p.

6. Danchuk A.I., Makhova T.M., Doronin S.Yu., Makhov S.V. et al., Butlerov Communications, 2016, Vol. 48, No 11, pp. 123131.

7. Kampalanonwat P., Supaphol P., Ind. Eng. Chem. Res., 2011, No 50, pp. 11912-11921. DOI: $10.1021 / \mathrm{ie} 200504 \mathrm{c}$.

8. Chernova R.K., Kulapina E.G., Rusanova T.Yu., Doronin S.Yu. Praktikum po analiticheskoj himii. Pt. 1. Uchebnoe posobie. Saratov, Saratov state university Publ., 2015, 120 p.
212. pp. 317-331.

10.Лосев В.Н., Дидух С.Л., Буйко Е.В., Метелица С.И., Трофимчук А.К. // Аналитика и контроль. 2009. Т. 13. № 1. С. 33-39.

11.Жантуаров С.Р., Умирзаков А.Г., Мартемьянов Д.В. // «Изучение свойств глауконита, модифицированного нановолокнами оксигидроксида алюминия», сборник трудов XIX Международной научнопрактической конференции студентов, аспирантов и молодых ученых. 15-19 апреля 2013 г. Томск. 2013. С. 427-428.

12.Костин А.В., Мосталыгина Л.В., Бухтояров О.И. // Сорбиионные $u$ хроматографические проиессы. 2012. Т. 12. № 6. C. 949-957.

13.Лурье Ю.Ю. Справочник по аналитической химии. М. Химия. 1971. С. 266269.

14.Абрамов А.А. Собрание сочинений. Т.7: Флотация. Реагенты-сорбиратели. Учебное пособие. М. Горная книга. 2012. 656 с.

15. Ларионов Н.С., Боголицын К.Г., Богданов М.В., Кузнецова И.А. // Химия растительного сырья. 2008. № 4. С. 147-152.

9. Hua M., Zhang S., Pan B., Zhang W., Lv L., Zhang Q., Journal of Hazardous Materials, 2012, Vol. 211-212, pp. 317-331. DOI: 10.1016/j.jhazmat.2011.10.016.

10. Losev V.N., Diduh S.L., Bujko E.V., Metelica S.I., Trofimchuk A.K. Analytics and Control, 2009, Vol. 13, No 1, pp. 33-39.

11. Zhantuarov S.R., Umirzakov A.G., Martem'janov D.V., «Izuchenie svojstv glaukonita, modificirovannogo nanovoloknami oksigidroksida aljuminija», XIX International scientific and practical conference of students, post-graduates and young scientists, April 15-19, 2013, Tomsk, 2013, pp. $427-428$.

12. Kostin A.V., Mostalygina L.V., Buhtojarov O.I., Sorbtsionnye i khromatograficheskie protsessy, 2012, Vol. 12, No 6, pp. 949-957.

13. Lur'e Ju.Ju. Spravochnik po analiticheskoj himii, M., Himija, 1971, pp. 266-269.

14. Abramov A.A. Sobranie sochinenij. Vol. 7, Flotacija. Reagenty-sorbirateli. Uchebnoe posobie, M., Gornaja kniga, 2012, 656 p.

15. Larionov N.S., Bogolicyn K.G., Bogdanov M.V., Kuznecova I.A., Chemistry of plant raw material, 2008, No 4, pp. 147-152. 
Данчук Александра Ильинична - аспирант кафедры аналитической химии и химической экологии Института химии СГУ им. Н.Г. Чернышевского, Саратов.

Грунова Юлия Валерьевна - магистрант кафедры аналитической химии и химической экологии Института химии СГУ им. Н.Г. Чернышевского, Саратов

Доронин Сергей Юрьевич - д.х.н., профессор кафедры аналитической химии и химической экологии Института химии СГУ им. Н.Г. Чернышевского, Саратов

Лясникова Александра Владимировна д.т.н., зав. кафедрой «Физическое материаловедение и биомедицинсая инженерия», СГТУ им. Ю.А. Гагарина, Саратов
Danchuk Alexandra I. - postgraduate student, department of analytical chemistry and chemical ecology, Institute of chemistry, Saratov State University, Saratov, e-mail: alexandradanchuk@yandex.ru

Grunova Yuliya V. - master student, department of analytical chemistry and chemical ecology, Institute of chemistry, Saratov State University, Saratov, e-mail: yulia.grunowa@yandex.ru

Doronin Sergey Yu. - prof., PhD (Chemistry), department of analytical chemistry and chemical ecology, Institute of chemistry, Saratov State University, Saratov, e-mail: doroninsu@mail.ru

Lyasnikova Alexandra V. - PhD (Technical Sciences), Head of department of «Physical materials science and biomedical engineering», Saratov State Technical University, Saratov, e-mail: kafbma2011@yandex.ru 